\title{
Chloride Urine Excretion Rate
}

National Cancer Institute

\section{Source}

National Cancer Institute. Chloride Urine Excretion Rate. NCI Thesaurus. Code C117832.

A determination of the amount of chloride being excreted in urine over a defined period of time. 